\title{
Experimentação prática de encaixes em fabricação digital subtrativa.
} Practical experimentation of joints in subtractive digital manufacturing.

\author{
Luiz Alberto Fresl Backheuser \\ Universidade Presbiteriana Mackenzie \\ luiz.backheuser@mackenzie.br \\ Eduardo Luisi Paixão Silva Campolongo \\ Universidade Presbiteriana Mackenzie \\ eduardocampolongo@hotmail.com
}

\begin{abstract}
Aiming the application of digital fabrication in the production of architectural structures, the experimentation described in this paper has focused on the production of joints of gantry components machined in a CNC Router. Our goals are, in the long terms, to reduce costs in the production of social housing through the application of technologies already consolidated in other areas of knowledge. Thus, the article will describe the production of a real-scale prototype of a part of the structure of a residential unit, adapting an Open Source construction system (Wikihouse).
\end{abstract}

Keywords: Wikihouse, Digital fabrication, Wood joints, CNC router.

\section{Antecedentes}

O grupo de pesquisa Teoria e Projeto na Era Digital (TPED) da Faculdade de Arquitetura e Urbanismo (FAU) da Universidade Presbiteriana Mackenzie (UPM) participou em parceria com outras instituições de uma série de estudos sobre a utilização das Tecnologias da Informação e Comunicação (TIC), na produção de habitações de interesse social, com foco no Programa Minha Casa Minha Vida (PMCMV). Um primeiro modelo em escala real nos mostrou dificuldades que não imaginávamos, e quem vem sido sanadas aos poucos em pesquisas paralelas. Entre essas dificuldades, as conexões (Wood Joints) dos componentes usinados digitalmente que estávamos utilizando se mostraram frágeis para a escala de construção que almejamos. Assim, o grupo de pesquisa dedicou parte de seus esforços na identificação e solução de novas conexões. Para testar sua implementação, foi criado um modelo estrutural inspirado no sistema Wikihouse, usinado e montado na FAU UPM.

\section{Introdução}

O sistema Wikihouse é descrito como "[...] an open source project to reinvent the way we make homes. It is being developed by architects, designers, engineers, inventors, manufacturers and builders, collaborating to develop the best, simplest, most sustainable, high-performance building technologies, which anyone can use and improve." (wikihouse.cc. Acesso em 04 de setembro de 2017)

O presente trabalho mostra parte de uma pesquisa a longo prazo de desenvolvimento de uma edificação completa produzida a partir da fabricação digital subtrativa. No entanto, muitas etapas ainda devem ser futuramente vencidas, como vedações e instalações. A pesquisa ainda se encontra numa etapa anterior, definindo soluções estruturais.

\section{A primeira estrutura}

O grupo de pesquisa TPED com apoio financeiro da Financiadora de Estudos e Projetos (FINEP), desenvolveu ao longo de 2015 uma estrutura em pórticos usinados em uma fresadora CNC, baseada no sistema Wikihouse, que se integra a uma pesquisa mais ampla que busca verificar a viabilidade de implementação de um sistema de fabricação digital na produção de habitação de interesse social no Brasil, nomeadamente, no programa do Governo Federal PMCMV (Nardelli, 2016).

Essa primeira estrutura provou que apesar dos problemas, a linha de pesquisa é pertinente, e a aplicação de fabricação digital subtrativa pode vir a ser uma realidade na produção de habitação social em grande escala, incorporando as vantagens desses processos, como a racionalização da construção e a customização em massa.

Embora o sistema Wikihouse seja considere a utilização de compensados estruturais, a presente pesquisa utilizou Oriented Strand Board (OSB), uma vez que se trata de um material mais barato, portanto, pertinente na busca de habitação de custos reduzidos. Embora o material não apresente as mesmas qualidades estruturais de outras opções, pretende-se provar que ele pode vir a ser utilizado de maneira efetiva e permanente. Deve-se lembrar que o OSB já foi utilizado em muitos exemplos construídos no sistema Wikihouse. 


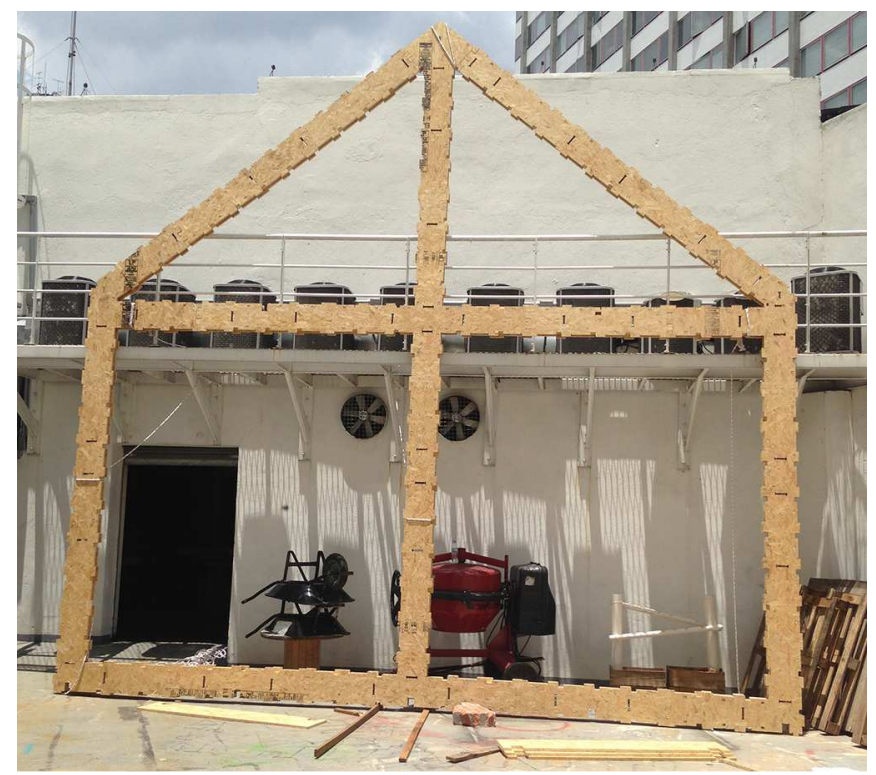

Figura 1 - Pórtico em escala real

Embora tenha sido feita baseada nas dimensões do sistema Wikihouse, nossa primeira estrutura mostrou fragilidades construtivas, especialmente nas juntas entre os componentes que formavam os pórticos. Os formatos excessivamente recortados e a dimensões reduzidas dessas juntas exigiram um considerável tempo de usinagem e romperam com facilidade, tanto durante a montagem quanto depois da estrutura erguida, evidenciando que não eram adequadas para uma estrutura nas dimensões de uma unidade do PMCMV.

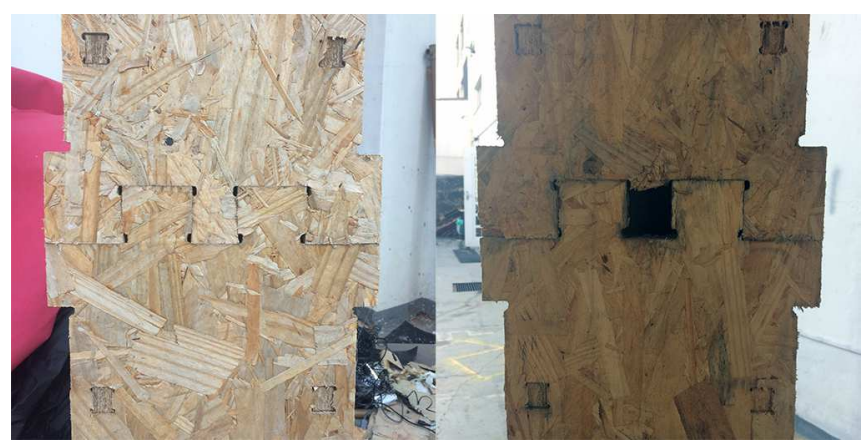

Figura 2 - Conexões utilizadas na primeira estrutura.

\section{Novas conexões}

Uma pesquisa de iniciação científica elaboradas por um dos alunos da graduação do grupo TPED, identificou uma série de conexões que pareciam convenientes para uma estrutura como a que almejamos. Dessas, duas foram destacadas, pela simplicidade de suas formas, o que poderia reduzir o tempo de usinagem, economizando horas de trabalho e desgaste do maquinário.

A primeira conexão se caracteriza pelo travamento a partir de cunhas. Ela é composta por dois grandes trapézios em forma de gancho, que ganham rigidez e estabilidade com um travamento composto por duas peças em formato de "U" e uma cunha.

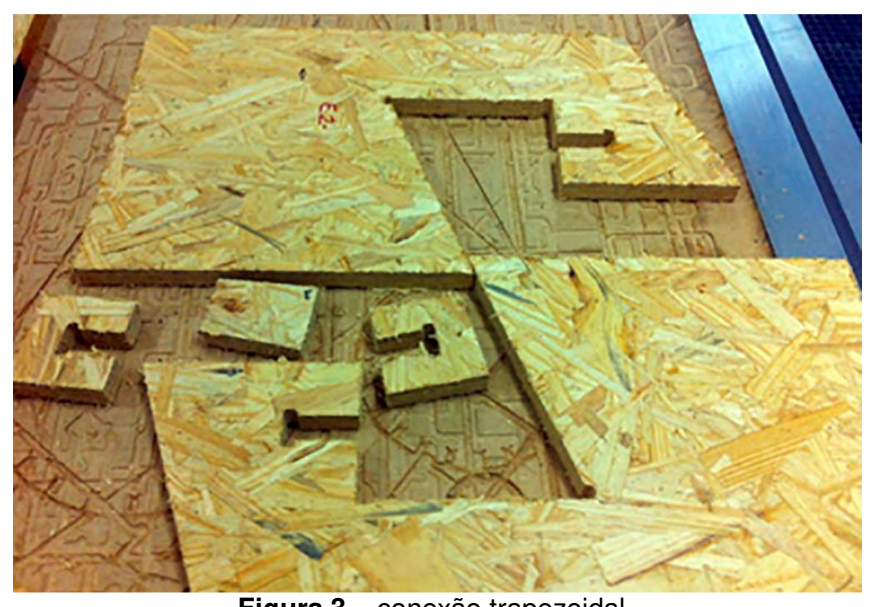

Figura 3 - conexão trapezoidal.

Este modelo desenvolvido assemelha-se ao modelo "S-joint" já utilizado no sistema Wikihouse, porém o formato em questão trabalha com encaixes retos e não em formato trapezoidal, o que disponibiliza maior área de contato entre as peças.

A segunda conexão se caracteriza por um formato circular em um sistema macho-fêmea. A forma sugere uma economia de tempo de usinagem, uma vez que não conta com aberturas vazias, uma vez que não conta com outros travamentos, nem com a chamada Orelha de Mickey Mouse, ou seja, o corte necessário para que a fresa faça um contorno de 90 graus.

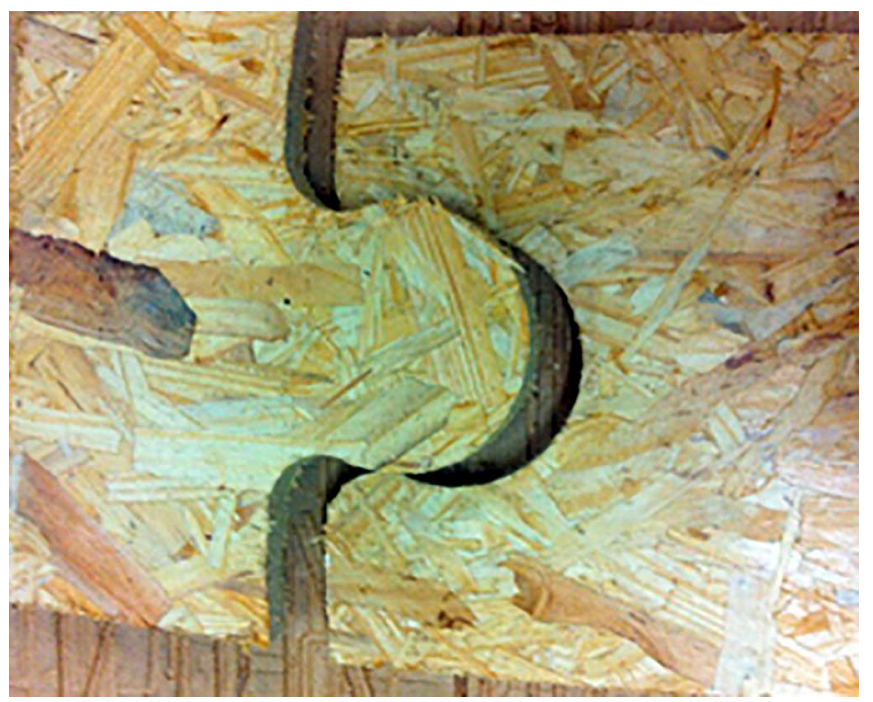

Figura 4 - conexão circular. 


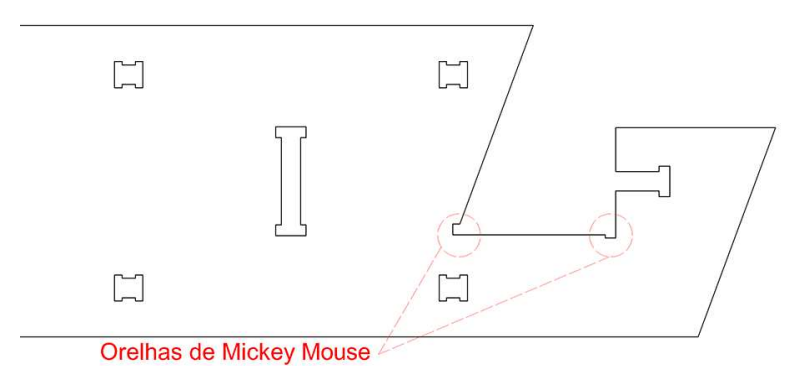

Figura 5 - Orelha de Mickey Mouse.

A pesquisa comparou os tipos de conexões a partir de três critérios: tempo de corte, quantidade de material desperdiçado e tempo de montagem.

A segunda conexão, de formato circular, foi usinada mais rapidamente e gerou menos resíduos que a conexão trapezoidal. No entanto, a rigidez da conexão circular se estabelece a partir da fricção entre as peças, exigindo que ambas as partes não tenham qualquer folga entre elas, o que dificultou sua montagem, prejudicando seu desempenho no terceiro critério de avaliação.

Essa pesquisa de apoio não produziu peças grandes por falta de recursos financeiros, o que dificultou a avaliação da resistência mecânica dessas conexões. Esse quarto critério de avalição, o desempenho estrutural, deveria então ser aplicado na segunda grande estrutura que já vinha sendo planejada.

Decidiu-se que a conexão trapezoidal seria utilizada para a união entre os componentes que formariam os pórticos, uma vez que demandava menos tempo de montagem, por parecer mais estável por conta do travamento cunhado e por ser usada com mais frequência em exemplos internacionais.

A conexão circular foi, no entanto, utilizada amarrando os painéis do piso da nova estrutura, ainda com um caráter experimental.

\section{A segunda estrutura}

\section{Concepção}

A nova estrutura foi concebida pelos alunos e professores do TPED de maneira que simulasse as demandas estruturais de parte de uma unidade similar aos padrões do PMCMV. As limitações de recurso e tempo não permitiu o desenvolvimento de um modelo maior, o que também não era conveniente para essa etapa da pesquisa, cujo objetivo era testar as novas conexões. Outras deficiências e elementos por resolver do modelo original seguem sendo resolvidas em pesquisas paralelas.

O grupo contava com 20 painéis de OSB de 18,33mm de espessura, provenientes de experimentações anteriores. Além disso também teve de enfrentar a falta de um técnico disponível para a operação da fresadora. Dois alunos se voluntariaram para a usinagem das peças, no tempo demandado para que a estrutura pudesse ser montada no período da Semana Viver Metrópole (SVM), promovida pela Universidade.

Assim, uma proposta foi elaborada de maneira a atender as limitações existentes, mas que ainda assim mostrasse as potencialidades formais do sistema.

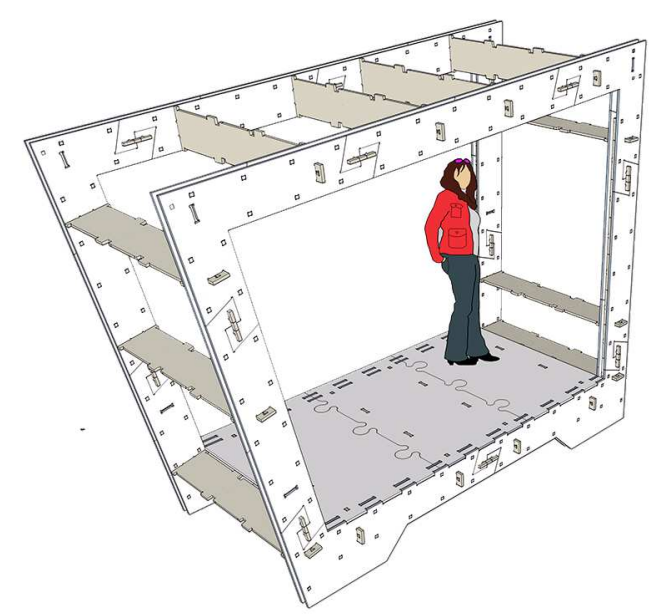

Figura 6 - Proposta para a segunda estrutura.

Embora a escolha do desenho das conexões já estivesse definida, um aspecto importante não havia sido contemplado na pesquisa de iniciação científica supracitada.

Para que a conexão trapezoidal fosse efetiva, haveria que se considerar uma folga (stock) entre as partes que permitissem uma montagem fácil, mas que ao mesmo tempo não eliminasse o contato necessário entre elas, comprometendo seu desempenho estrutural.

Assim foram feitos estudos de cortes, afim de verificar quanto a fresa deveria cortar além do necessário, para que houvesse simultaneamente o atrito e a folga (stock) ideais.

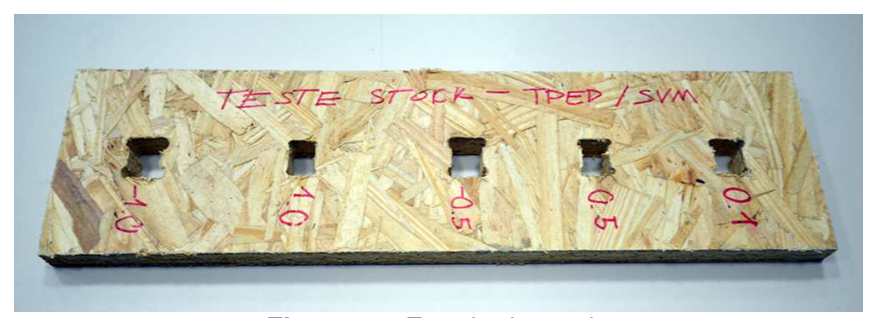

Figura 7 - Estudo de stock.

Em seguida um pequeno modelo da conexão trapezoidal com o Stock adequado foi usinado confirmando a efetividade do ensaio anterior. 


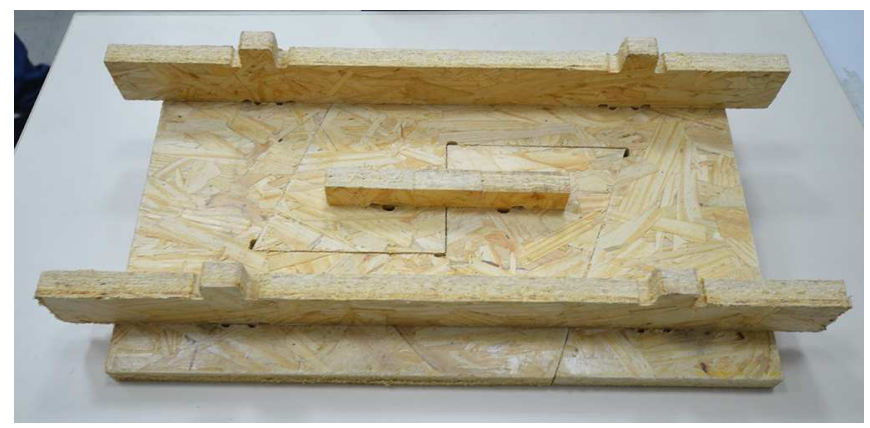

Figura 8 - Estudo da conexão trapezoidal com o stock adequado.

A não previsão de painéis de vedação e as conexões trapezoidais eliminaram uma grande quantidade de recortes previstos no sistema Wikihouse e executados na primeira estrutura usinada pelo grupo de pesquisa, o que se esperava que reduzisse o tempo de corte dos painéis.

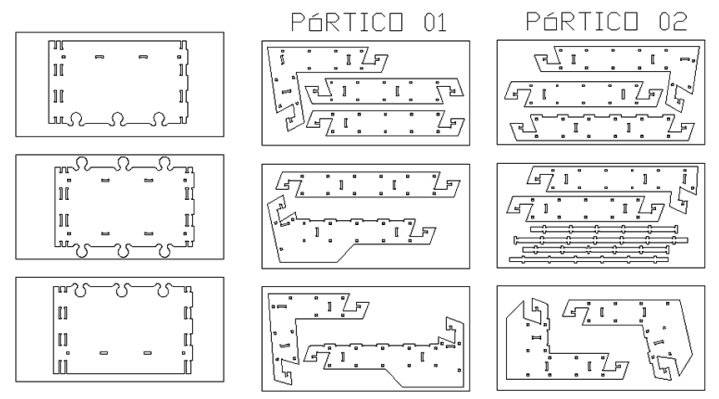

Figura 9 - Componentes distribuídos nos painéis de OSB.

\section{Usinagem}

Ao contrário do que se esperava, o tempo médio de usinagem de cada painel foi similar ao da primeira estrutura, aproximadamente uma hora, uma vez os componentes foram melhor dimensionados em função do tamanho dos painéis de OSB, cabendo, assim, mais componentes por painel.

Perfurações menores, necessárias para o encaixe de travamentos perpendiculares, ainda exigiram não recortes, mas a completa remoção do material (pocketing), uma vez que a liberação de peças pequenas frequentemente travavam o funcionamento da fresa, chegando até a quebrá-las, além de obstruir o sistema de sucção de serragem, o que contribuiu com a manutenção do tempo de usinagem.

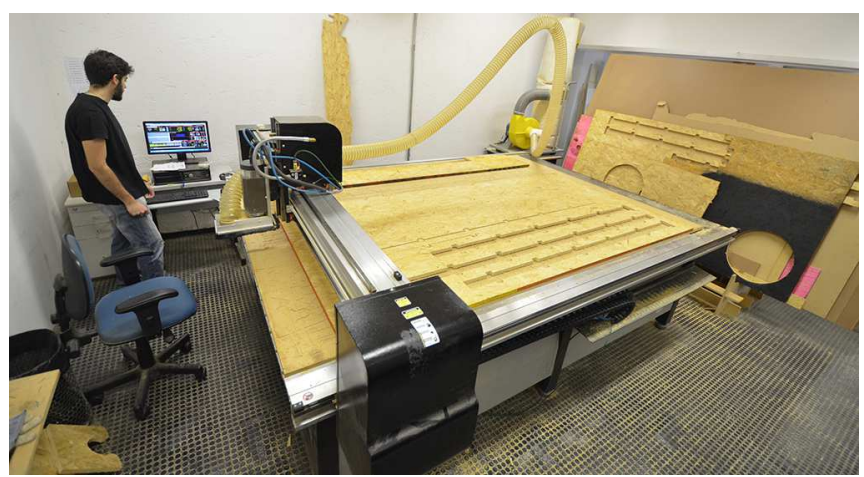

Figura 10 - Aluno do grupo TPED operando a fresadora.
Foram necessários cerca de uma hora de usinagem por painel, obrigando os alunos a trabalharem em três períodos do dia (manhã, tarde e noite) por uma semana, pois além da usinagem, muitos minutos eram gastos trocando e fixando os painéis de OSB na máquina, além da remoção e armazenagem das peças usinadas em outro ambiente.

Toda a estrutura foi usinada em 6 dias, de segunda a sábado, em três períodos diários de 4 horas cada, num total de 72 horas de trabalho. Foram consumidos 19 painéis de OSB e uma fresa de $\varnothing 6 \mathrm{~mm}$ e 3 cortes.

\section{Montagem}

A conclusão da usinagem coincidiu com o início da chamada Semana Viver Metrópole (SVM), um evento anual da FAU UPM, quando as aulas regulares são interrompidas e uma série de palestra, seminários e workshops ocupam o tempo dos alunos, abordando os mais variados assuntos relacionados à arquitetura e o urbanismo.

Assim, decidiu-se que a montagem da nova estrutura seria incluída entre atividades da SVM, permitindo que alunos não vinculados ao grupo de pesquisa TPED participassem do processo. Foram abertas um número de vagas e os alunos foram admitidos por ordem de inscrição.

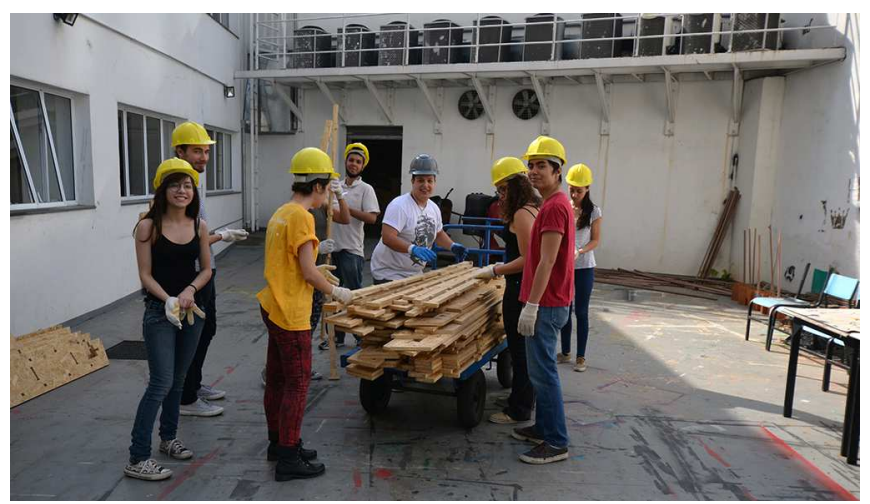

Figura 11 - Alunos da FAU UPM e os componentes já usinados.

A primeira etapa da montagem se deu com o recolhimento dos componentes usinados na marcenaria da universidade, até o interior do campus, onde a estrutura teria maior visibilidade e poderia ser efetivamente inserida nas atividades da SVM.

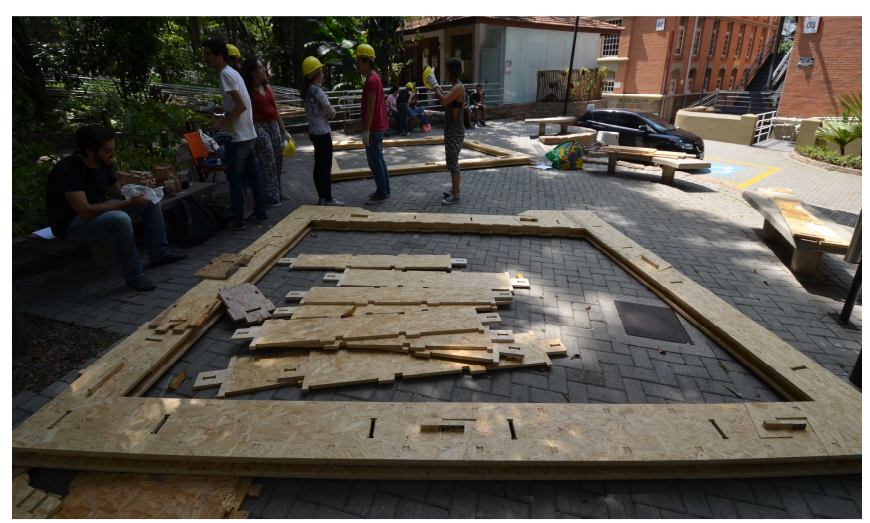

Figura 12 - Os dois pórticos montados no chão. 
A montagem se deu em três etapas: primeiro, a união dos componentes dos dois pórticos no chão, considerando que cada pórtico é composto de duas camadas de componentes, em seguida, suas elevações e, por fim, a conexão de ambas as partes, com os travamentos transversais e 0 piso, consolidando o sistema estrutural.

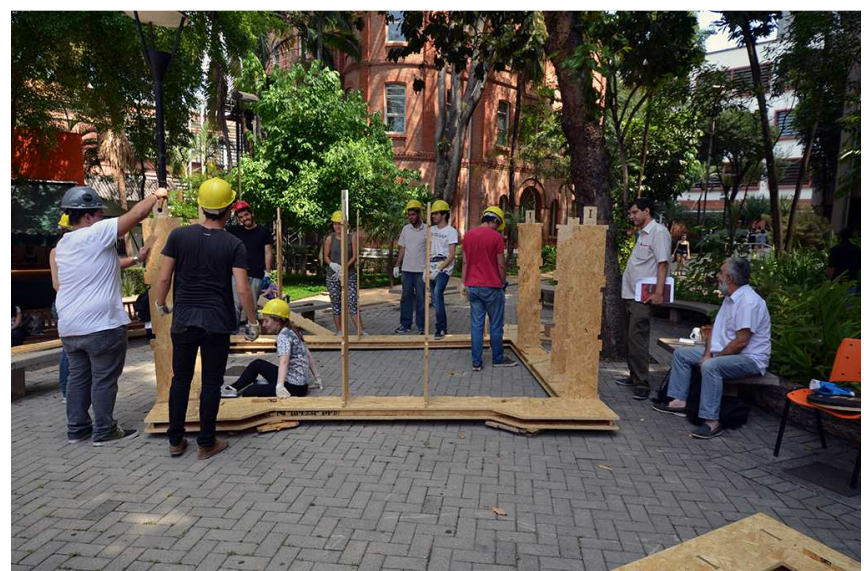

Figura 13 - Fixação dos travamentos perpendiculares.

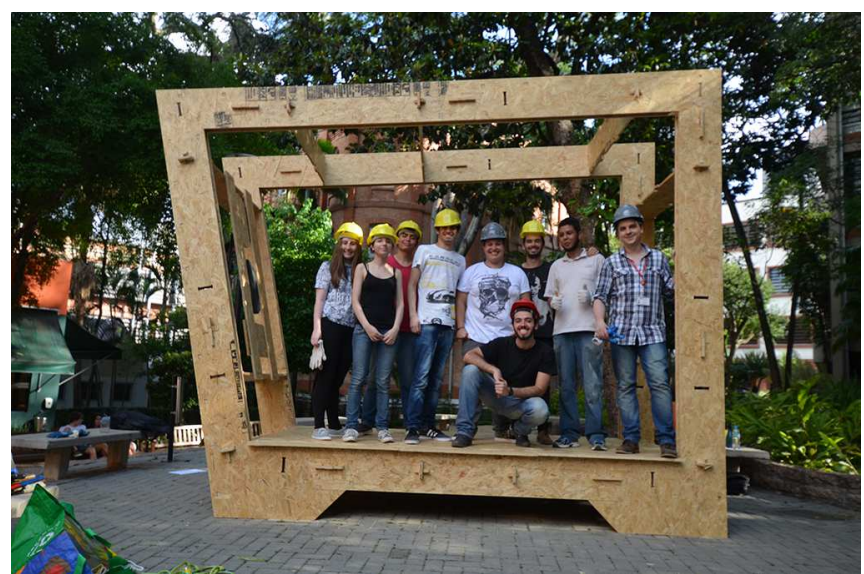

Figura 14 - Estrutura concluída.

\section{Conclusões}

O desenvolvimento da segunda estrutura se insere numa pesquisa mais ampla que, como foi dito anteriormente, busca a aplicação de sistemas subtrativos de fabricação digital à produção de habitação social em larga escala.

Essa segunda experiência trouxe um avanço considerável no desenvolvimento do projeto como um todo, aumentando a experiência do grupo, reduzindo os caminhos possíveis para o avanço dos trabalhos.

O material escolhido, OSB, que na primeira experiência pareceu inadequado, com a revisão das conexões teve um comportamento melhor, resistindo desprotegido por quase dois meses a chuvas torrenciais que castigaram a cidade de São Paulo no final do ano de 2016. Assim, o material parece hoje adequado a proposta, pois demonstrou boa resistência mecânica aliada a um baixo custo de aquisição.

No entanto ainda há muito o que se fazer, incluindo a adaptação de instalações à estrutura, e a definição de possíveis sistemas de vedação.

Paralelemente, também vem sendo desenvolvida uma plataforma digital onde os futuros possíveis usuários possam definir especificidades no objeto, efetivando uma customização de cada unidade residencial, uma das potencialidades da fabricação digital. Para tanto, o projeto vem sendo parametrizado, o que passa por questões ainda por resolver como a definição de um padrão de coordenação modular.

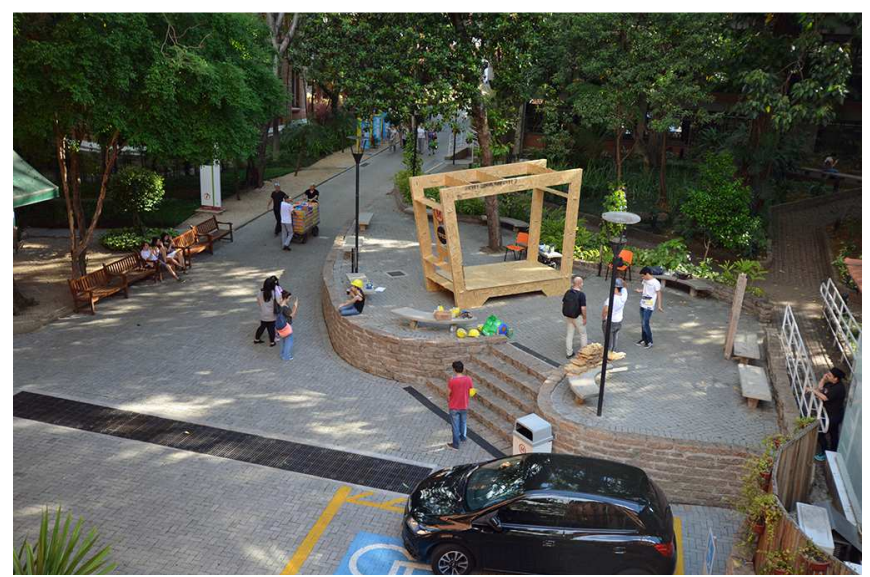

Figura 15 - Estrutura concluída.

\section{Agradecimentos}

Agradecemos à Faculdade de Arquitetura e Urbanismo da Universidade Presbiteriana Mackenzie, ao Diretório Acadêmico (DAFAM), aos alunos bolsistas e voluntários, à DS4 Laser \& Router e ao arquiteto Affonso Orciuoli.

\section{Referencias}

NARDELLI, E. S.; BACKHEUSER, L. A. F. Sistema Wikihouse aplicado ao Programa Minha Casa Minha Vida. In: XX Congreso de la Sociedad Iberoamericana de Gráfica Digital, SIGraDI: crowdthingking, 2016, Buenos Aires. XX Congreso de la Sociedad Iberoamericana de Gráfica Digital, SIGraDI: crowdthingking. São Paulo: Blucher, 2016. v. 1.

APA 6th citation guide for formatting references. (n.d.) Retrieved from http://www.wikihouse.cc/

Kolarevic, B. (Ed.). (2004). Architecture in the digital age: design and manufacturing. Taylor \& Francis. 